\title{
Orthography Shapes Semantic and Phonological Activation in Reading
}

\author{
HUI-WEN CHENG and CATHERINE L. CALDWELL-HARRIS \\ Boston University
}

\section{Introduction}

Reading is a process of retrieving graphic, semantic, and phonological information from printed words. Psycholinguists are increasingly aware that different orthographies encode semantics and phonology with different amounts of transparency. The activation of semantic and phonological information during reading may thus differ across orthographies. However, priming studies have produced mixed results on this question, leading some researchers to claim that Chinese orthography produces the same pattern of phonological activation as does English orthography (e.g., Perfertti and his colleagues 1992, 1998, 2008). The present study approaches this issue using a novel task that may avoid some of the methodological problems of priming studies: semantic substitution errors made by native Chinese readers.

The transparency of symbol-sound correspondence has been used to categorize alphabetic orthographies (Liberman et al. 1980). Shallow orthographies, like Spanish and Serbo-Croatian, have relatively consistent and transparent letter-phoneme correspondences. Deep orthographies, like English and Arabic, have relatively inconsistent and opaque letter-phoneme correspondences. The Orthographic Depth Hypothesis (ODH) states that when reading printed words, shallow orthographies activate more phonological information, whereas deep orthographies activate more graphic information (Katz and Frost 1992). In other words, phonological recoding is more important for shallow orthographies, while visual-based direct access strategy is more important for deep orthographies, although both strategies are necessary for reading every orthography. Using naming tasks, Frost et al. (1987) showed that the role of phonological recoding is more important in Serbo-Croatian than in English, and more important in English than in Hebrew. They also reported a relatively strong effect of semantic facilitation in Hebrew, a small but significant effect in English, and no facilitation 
in Serbo-Croatian. Similarly, Tabossi and Laghi (1992) found stronger semantic priming effects in English than in Italian for naming words aloud. These findings were challenged by Baluch and Besner (1991), who proposed that the cross-orthography differences might result from the inclusion of nonwords in the stimulus lists, since nonwords encourage the use of a prelexical naming strategy. These uneven and conflicting findings indicate that additional research on semantic activation is warranted.

It is well known that Chinese orthography has a relatively opaque symbol-sound correspondence. If included in the continuum of orthographic depth, Chinese would be placed at the deep end. Although $80 \%$ to $85 \%$ of Chinese characters consist of a semantic radical and a phonetic radical (Kang 1993; Zhou 1978), phonetic radicals are not reliable cues for pronunciation (Zhou 1980). In contrast, semantic radicals are usually directly related to character meaning (Wang 1997). Therefore, there was an assumption that reading Chinese is solely meaning-based (e.g., Weekes et al. 1998, Zhou and Marslen-Wilson 1996). This view was refuted by studies of Perfetti and his colleagues, who showed that phonological activation appears strongly at the early stage of Chinese visual word recognition (Perfetti and Tan 1998, Perfetti and Zhang 1991, Perfetti and Zhang 1995). For example, in 2 primed-naming experiments, graphic, phonological, and semantic priming effects occurred at $43 \mathrm{~ms}, 57 \mathrm{~ms}, 85 \mathrm{~ms}$ respectively, and all priming effects were at least 50ms (Perfetti and Tan 1998). Based on these studies, Perfetti and his colleagues proposed the Universal Phonological Principle (UPP) to argue that phonological activation is obligatory across writing systems. However, Chen and Shu (2001) were only able to replicate Perfetti and Tan (1998) in graphic priming effects, but not in semantic and phonological priming effects. Wu and Chen (2000) also reported that with several attempts, they still could not have similar results as Perfetti and Zhang (1991). Moreover, other research found that phonology plays no role or a less important role in Chinese reading (Chen et al. 1995, Liu et al. 2006, Shen and Forster 1999). Given the lack of consensus in semantic and phonological activation in reading Chinese, additional research is necessary to increase the understanding of the process of Chinese reading.

This study will investigate whether Chinese orthography differs from English orthography in terms of the relative activation of semantic versus phonological information. Do Chinese characters evoke greater activation of semantic information compared to phonological information? Do they trigger greater activation of semantic information than English orthography? Moreover, few studies have examined Chinese reading and alphabetic reading with the same experimental design. The present study fills these gaps in the literature by examining a previously unstudied phenomenon: semantic substitutions that occur during reading outloud tasks.

Semantic substitution errors are errors made by substituting the target word (e.g., yell) with another word which is semantically related to the target word (e.g., 


\section{Semantic and Phonological Activation in Reading}

shout) (Abu-Rabia and Taha 2004, Béland and Mimouni 2001). It is a type of error that deep dyslexic English readers, but not normal English readers, usually make (Barry 1984, Coltheart 1980). However, in a study conducted in China and Taiwan to examine the processing of Chinese simplified and traditional scripts, we observed Chinese readers making semantic substitution errors when reading aloud never-seen-before Chinese passages from a computer screen. This paper aims to report this finding. It has been argued that the occurrence of semantic substitutions in alphabetic readers with deep dyslexia results from the deficit of phonological retrieval (Laine et al. 1990). Given that Chinese orthography encodes phonological information in an opaque manner, we speculate that it is this characteristic that leads to weak phonological activation which in turn yields semantic substitutions.

\section{$1 \quad$ The Current Study}

Two experiments were conducted to investigate how frequently native Chinese speakers make semantic substitution occurs while reading aloud from novel (i.e., never seen before) passages.

\section{$1.1 \quad$ Experiment 1}

Experiment 1 was a passage read-aloud task performed by native Chinese speakers in China and Taiwan.

\subsubsection{Materials}

The stimuli consisted of 12 Chinese short passages selected from magazine articles published in China or Taiwan. They varied in three levels of difficulty: humorous stories, general current affairs, and technical scientific reports. The length of the passages ranged from 103 to 210 Chinese characters (mean $=176.5$, $\mathrm{SD}=28.36$ )

\subsubsection{Participants}

Participants were 29 Chinese college students (mean age $=22.3$ yrs), 25 Chinese middle school students (mean age $=12.7 \mathrm{yrs}$ ), and 25 Taiwanese middle school students (mean age $=13.2 \mathrm{yrs}$ ). The Chinese students were recruited from Beijing and the Taiwanese students were recruited from Taipei. They were all normal native Chinese readers without any reading disabilities.

\subsubsection{Procedure}




\section{Hui-wen Cheng \& Catherine Caldwell-Harris}

Participants were given no opportunity to preview the passages before they were asked to read aloud. In other words, the time when they read one passage aloud was also the first time they saw the passage. All passages, 6 passages in simplified script and 6 passages in traditional script in a counterbalanced design, were presented to every participant on a computer screen one at a time in random order ${ }^{1}$. Participants were told to read each passage aloud at their normal reading rate. They pressed the space bar as soon as they finished each passage reading, allowing reading times to be automatically recorded. An experimenter sat next to the participants and marked the verbal errors on hard copies of the reading texts.

\subsubsection{Results}

Although participants in Experiment 1 read in their familiar script as well as in their unfamiliar script, only the data from reading familiar script were analyzed. Thus, the data reported here consists of Chinese students reading in simplified script and Taiwanese students reading in traditional script. The rationale is that we do not want to count the semantic substitution errors resulted from the unfamiliarity of script. When reading an unfamiliar Chinese script, the common scenario is that a reader would try to guess the characters which he cannot recognize based on the context, which often results in a semantic substitution error.

The errors made by the participants during the read aloud task were categorized into 3 main categories: pure substitution errors, combined substitution errors, and miscellaneous errors as defined below.

(I) Pure Substitution Errors: The replaced words have only one kind of linguistic relation with the target words, either semantic, phonological or orthographic.

(i) Semantic substitution errors: The replaced words are related to the target words in meaning, without sharing any phonological or orthographic relationship. They could be similar in meaning (e.g., replacement of 由 $y o u 2^{2}$ 'from' with 從 cong2 'from'), be thematically related, or be taxonomically related (e.g., replacement of 問 wen4 'to ask' with 說 shuol 'to say').

(ii) Phonological substitution errors: The replaced words are related to the target words in pronunciation. They share at least 2 phonemes (e.g., replacement of 光 guang1 'light' with 廣 guang3 'wide'; replacement of 風 feng1 'wind' with 方 fangl 'square'). There is no semantic or orthographic relation between the replaced words and the target words.

(iii) Orthographic substitution errors: The replaced words are related to the target

\footnotetext{
${ }^{1}$ This task is part of our another study which investigated the effect of simplified and traditional Chinese scripts on reading Chinese. Therefore, participants were asked to read in the 2 different Chinese scripts.

2 The number following the pinyin of each character refers to the tone of the character.
} 


\section{Semantic and Phonological Activation in Reading}

words in form. They share at least one character component (e.g., replacement of 運 yun4 'transport' with 連 lian2 'link'; replacement of 問 wen2 'to ask' with 間 jianl 'between'). There is no semantic or phonological relation between the replaced words and the target words.

(II) Combined Substitution Errors: In this type of error, the replaced words have 2 or 3 kinds of linguistic relation with the target words.

(iv) Semantic + Phonological substitution errors: The replaced words are related to the target words in meaning and pronunciation (e.g., replacement of 顆 kel 'classifier for round objects' with 個 ge 'classifier for anything'). There is no orthographic relation between the replaced words and the target words.

(v) Semantic + Orthographic substitution errors: The replaced words are related to the target words in meaning and form (e.g., replacement of 至 zhi4 'to' with 到 dao4 'to'; replacement of 線 xian4 'thread' with 絲 sil 'thin thread'). There is no phonological relation between the replaced words and the target words.

(vi) Phonological + Orthographic substitution errors: The replaced words are related to the target words in pronunciation and form (e.g., replacement of 忱 chen 2 'sincerity' with 枕 zhen3 'pillow'). There is no semantic relation between the replaced words and the target words.

(vii) Semantic + Phonological + Orthographic substitution errors: The replaced words are related to the target words in meaning, pronunciation, and form (e.g., replacement of 氨 anl 'ammonia' with 氮 dan4 'nitrogen').

(III) Miscellaneous Errors: Miscellaneous errors including the following error types.

(viii) Insertion: A word was inserted into the passage during reading aloud.

(ix) Inversion: The order of two words was switched.

(x) Omission: A word presented in the passage was omitted during reading aloud.

(xi) Morphological substitution errors: The replaced word is derived from the target word or vice versa (e.g., replacement of person with personality). This type of error only occurred to native English readers in Experiment 2, but not to native Chinese readers in Experiment 1 and 3.

(xii) Function-word substitution errors: A function word (e.g., the) is replaced with another function word (e.g., a). This type of error, like morphological substitution errors, only occurred to native English readers.

Based on the classification described above, the percentage of error types was calculated and appears in (1). The most frequent category of error made by the Chinese readers is semantic substitution. It included $57 \%$ of the errors, indicating that native Chinese readers frequently make semantic substitution errors. Given that in English reading, semantic substitution is a characteristic mainly of English deep dyslexic readers, it was important to determine whether 


\section{Hui-wen Cheng \& Catherine Caldwell-Harris}

the observed semantic substitution errors were representative of the majority of readers or were confined to a subgroup or type of passage. A 3 (group) X 3 (level of readers) X 3 (level of passages) ANOVA was conducted to examine this question. The factor of group refers to Chinese college students, Chinese middle school students, and Taiwanese middle school students. Based on the reading rate in a silent reading task, all the participants were classified into 3 levels of readers: excellent readers, good readers, and poor readers. The 3 levels of passages were humorous stories, general current affairs, and technical scientific reports. None of the 3 factors had a main effect. This result indicated that semantic substitution errors occurred for all passage difficulty levels, and regardless of whether participants read simplified or traditional script, were college students or middle school students, or were good or poor readers. Moreover, over $90 \%$ of Chinese participants (72 out of 79) made semantic substitution errors. We therefore concluded that semantic substitution is a robust effect for native Chinese readers.

(1) Percentage of error type from the Chinese group's data

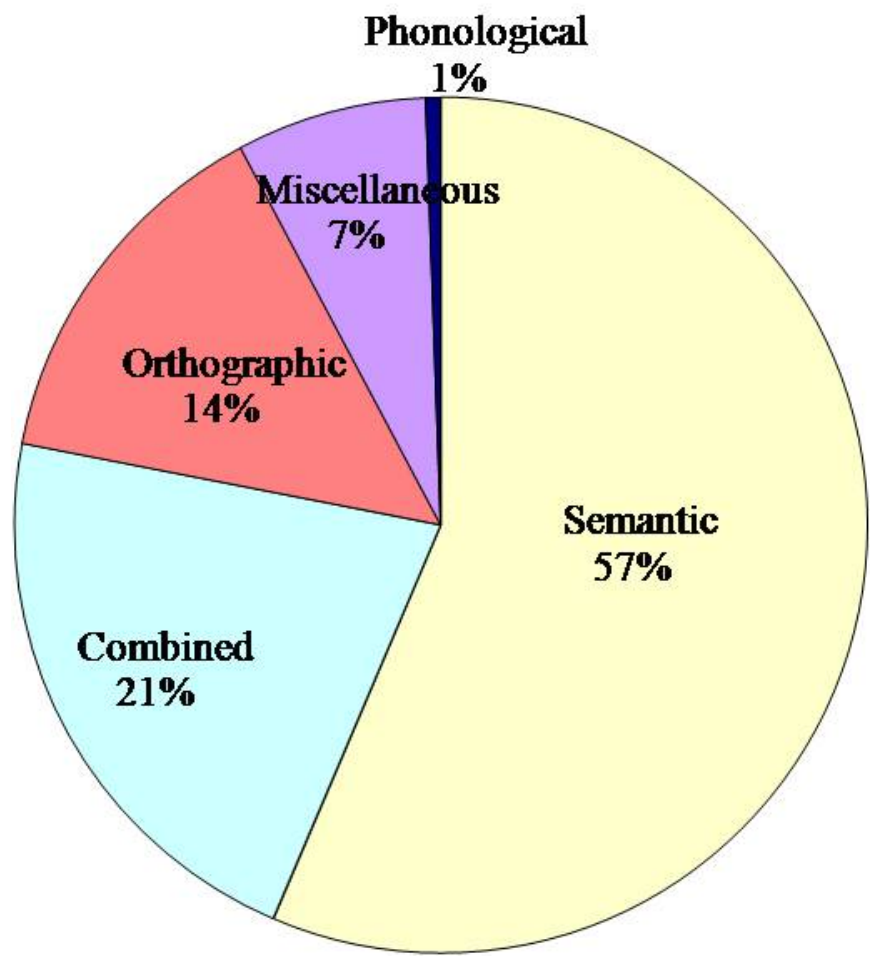

\section{$1.2 \quad$ Experiment 2}

Native English speakers in Experiment 2 also performed a read-aloud task to serve as a comparison group to the native Chinese speakers in Experiment 1. The purpose of this experiment was to confirm that making semantic substitution errors when reading never-before-seen passages aloud is a particular phenomenon 


\section{Semantic and Phonological Activation in Reading}

for native Chinese readers but not for native English readers. We speculated that the occurrence of semantic substitution errors resulted from retrieving words from memory. When performing a read-aloud task, the eyes can proceed ahead of the word being pronounced. It is likely that decoding words resulted in a clear representation of meaning and a vague representation of pronunciation. When it was time to pronounce a specific word in the sentence, the phonological trace of that word may have been insufficiently activated to allow the native Chinese readers to produce the target word. Therefore, they selected a semantically related word from memory and sounded it out.

\subsubsection{Materials}

The stimuli were the English translation version of the same 12 Chinese short passages used in Experiment 1. The English passages were translated by a Chinese-English bilingual and edited by an English monolingual to ensure English-language naturalness. The length of the English passages ranged from 69 to 155 words $($ mean $=114.8, \mathrm{SD}=24.87)$.

\subsubsection{Participants}

Participants were 20 native English speakers without reading disabilities (mean age $=19.2 \mathrm{yrs}$ ). These participants will be referred to as the English readers or simply the English group.

\subsubsection{Procedure}

This experiment employed the same procedure as in Experiment 1.

\subsubsection{Results}

The errors that native English readers made were categorized into the same error categories as Experiment 1, and compared to the data of Chinese college students from Experiment 1. The distribution of error types between the 2 groups of college students is shown in (2). The biggest proportion of the errors made by Chinese college students were semantic substitution errors (54\%), whereas the biggest proportion of the errors made by native English readers were miscellaneous errors $(67.5 \%)^{3}$. Only $1.1 \%$ of the native English readers' errors were semantic substitution errors. An analysis showed that Chinese college students made 20 times more semantic substitution errors than native English readers ( $p<.01 ; 0.282$ vs. 0.012 errors per person per passage). The 2 language

\footnotetext{
${ }^{3}$ The miscellaneous errors that native English readers made were mainly morphological errors (37.6\%) and omission (32.3\%).
} 


\section{Hui-wen Cheng \& Catherine Caldwell-Harris}

groups did not differ in per-passage reading times, indicating the comparability of the 2 groups.

(2) Percentage of error type from Chinese college students' and American college students' data

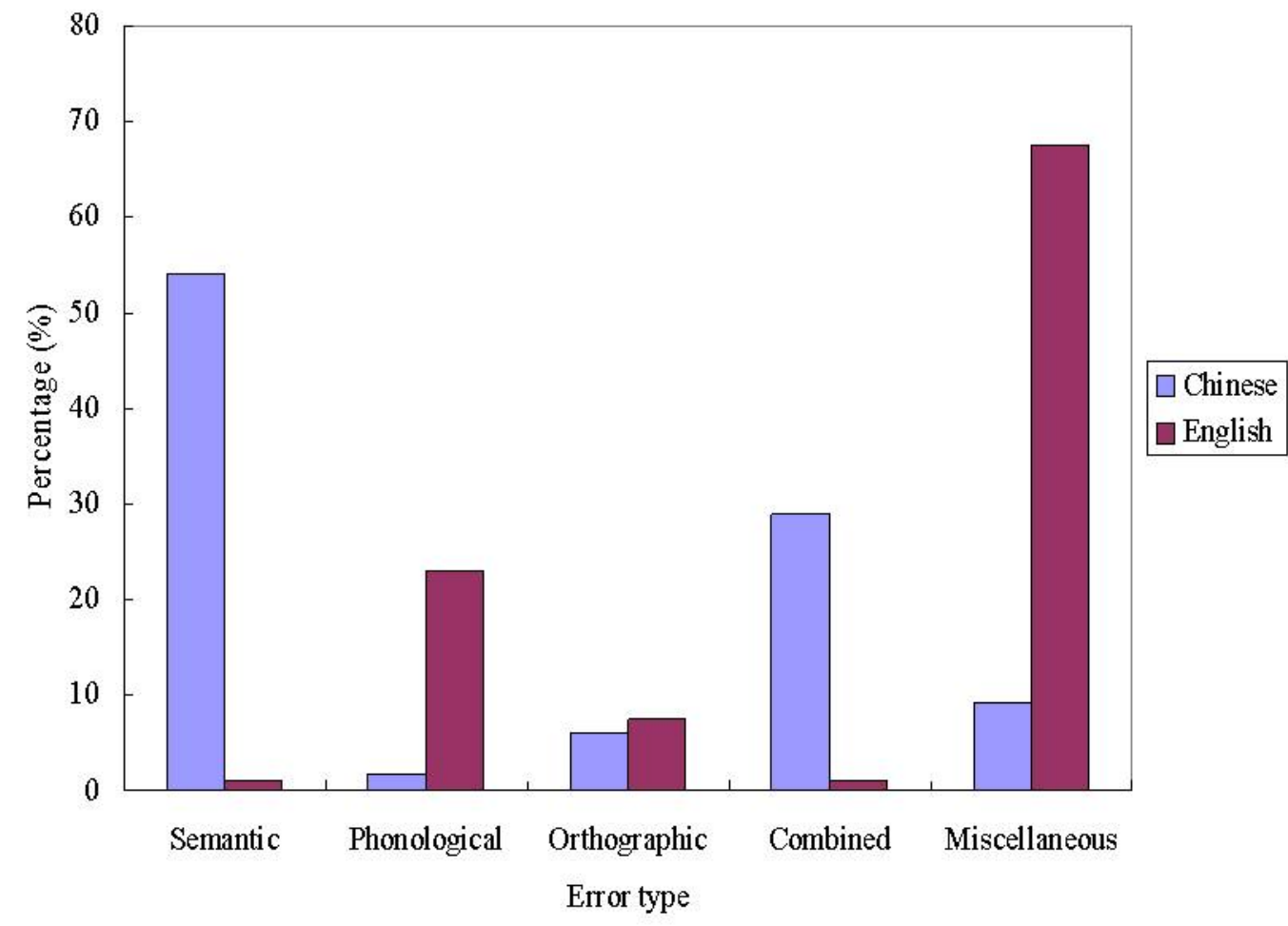

\section{$2 \quad$ General Discussion}

The major function of orthographies is to allow readers to access the meaning and pronunciation of spoken languages, and thus orthographies in the world encode semantic and phonological information. Our goal in the current paper is to demonstrate that the degree of transparency of semantic and phonological information is encoded differently from orthography to orthography. Alphabetic orthographies, for example, usually convey clues to pronunciation in a relatively more consistent and transparent manner than other orthographies. Does this difference in orthographies lead to different reading processes? This is the primary research question of the current study. Specifically, the present study investigated whether semantic and phonological information are processed in the same manner when reading English, an alphabetic orthography versus when reading Chinese, a morphosyllabic orthography. Different from previous studies using priming paradigms to explore this issue, we carried out a series of read aloud experiments and examined the occurrence of semantic substitution errors. 


\section{Semantic and Phonological Activation in Reading}

Semantic substitution is a characteristic of English deep dyslexic readers (Coltheart 1980). When reading word lists, English readers with deep dyslexia, but not normal English readers, tend to substitute a target word (e.g., yell) with another semantically related word (e.g., shout). One shocking finding of this study is that the native Chinese readers in China and Taiwan frequently made semantic substitution errors when reading never-before-seen Chinese texts aloud. Semantic substitution errors covered over $50 \%$ of errors made by the Chinese group. When reading the same passages in their native languages, the native Chinese readers in China made 20 times more semantic substitution errors than the native English readers. Over $90 \%$ of the Chinese group made semantic substitution errors. Regardless of whether they were college students or middle school students, of whether they were good readers or poor readers, whether they read traditional Chinese characters or simplified Chinese characters, or whether they read humorous stories or technical scientific reports.

We attribute occurrence of semantic substitution errors in read aloud tasks to the unique characteristic of Chinese orthography. Chinese characters are generally composed of a semantic radical and a phonetic component. Semantic radicals frequently provide reliable clues to the meaning of characters, yet phonetic components seldom provide reliable clues to the pronunciation of characters. In other words, semantic information is encoded in a more transparent and consistent manner than phonological information in Chinese orthography. The Orthographic Depth Hypothesis proposes that the transparently and consistently encoded information in an orthography is more strongly activated during reading. This suggests that semantic information is strongly activated when reading Chinese, while phonological information is weakly activated. A plausible consequence is that the mental activation of meaning is more robust and persists for a longer duration in short term memory. As we know, visual reading proceeds ahead of oral reading. It is likely that when a native Chinese reader needs to retrieve information from short term memory to pronounce the next character in the sentence, the mental representation of pronunciation of the targeted is too weak to allow verbalization. The reader may thus have some probability of verbalizing an alternative word (or morpheme) which conveys similar meaning. Because a specific meaning can be conveyed by several different characters, there are chances that the character that the reader retrieves is a semantically related character instead of the target character, yielding a semantic substitution error.

\section{$3 \quad$ Implications and Clarifications}

There has been a heated debate on whether reading processes are universal or language specific (Geva 2008). The current study appears to most strongly support the language-specific view, given our finding that native Chinese readers and native English readers processed semantic and phonological information 
differently in read aloud tasks. But clearly semantic and phonological information are both required for the two groups of readers to achieve the ultimate goal of pronouncing outloud written material. We advocate the co-existence of universal and language-specific reading processes. Chomsky's (1981) "Principles and Parameters Theory" could be applied to reading. There are some universal principles that are required in reading across languages, and there are also some parameters which vary based on the properties of each orthography. Reading in all the world's orthographies involves semantic, phonological, morphological, syntactic, and discourse information. The relative importance of each type of information is different in accordance to the linguistic structure of each language. For example, phonological processing plays a more important role in shallow orthographies like Spanish than in deep orthographies like English.

Is Chinese orthography pictographic, ideographic, or logographic? A pictographic orthography has pictorial graphs resembling physical objects. An ideographic orthography has graphs representing ideas or concepts. A logographic orthography has graphs representing a word or a morpheme. There are pictographs (e.g., 日 'sun' and 月 'moon') and ideographs (e.g., 上 'up' and 下 'down') in Chinese orthography, but they only constitute 3\% of Chinese characters according to Kanxi Dictionary (DeFrancis 1984). Chinese is logographic in the sense that each Chinese character represents a morpheme. However, each Chinese character also represents a syllable, a phonological unit. Moreover, $97 \%$ of Chinese characters known as semantic-phonetic compound characters comprise a semantic radical as well as a phonetic radical. Most Chinese characters (either the characters per se or the semantic radicals) provide somewhat reliable semantic information. In contrast, they usually do not provide reliable cues to the pronunciation of the whole character. Our findings revealed this characteristic of Chinese orthography salient. They nevertheless do not indicate that Chinese orthography is purely logographic.

Current findings can not be explained by "whole character" or other types of teaching methods. There are misconceptions about methods used to teach Chinese orthography, and whether native Chinese readers have an awareness of the internal structure of characters. Many people believe that each Chinese character is taught as one unit without reference to components. Learners thus would not be aware of the internal structure of a character, and would map the whole character to its meaning directly without exercising the symbol-sound correspondence. The first author of the current study received her primary school education in Taiwan and some of her friends received their primary school education in Mainland China. According to their personal experiences, primary school teachers in Taiwan as well as in Mainland China usually direct students' attention to semantic radicals when teaching new semantic-phonetic compound characters, although they rarely mention phonetic components. This is an understandable teaching strategy because semantic radicals are usually reliable cues to the meaning of the 


\section{Semantic and Phonological Activation in Reading}

whole character, yet phonetic components rarely provide reliable information for the pronunciation of the whole character. However, this teaching method does not entail native Chinese readers' lack of awareness of phonetic components. In fact, when encountering a novel character, every Chinese will try to look for clues to the pronunciation from the character components (Chan and Wang 2003, Chen and Yuen 1991, Shu and Wu 2006). One saying describing this strategy goes, “有 邊讀邊,沒邊讀中間” ('if there is a component on either side, pronounce the characters as the pronunciation of the side component, otherwise, pronounce the character as the pronunciation of the middle component'). Many studies have shown that native Chinese readers are aware of phonetic components, and are able to make use of them to figure of the pronunciation of novel or pseudo characters. For example, Chen and Yuen (1991) argued that "all Chinese readers, by default, rely on the phonetic component to read the pseudocharacters". Shu and Wu (2006) claimed that their study "provides clear evidence that children are sensitive to the partial information a phonetic provides for character pronunciation, and OPC [i.e., orthography-phonology correspondence] knowledge is also important in learning and memorizing novel compound characters." It is well known that children are capable of figuring out the generalization rules in their native language without explicit instructions. This phenomenon might be also applicable to the case of learning to read in one's native language. Although native Chinese readers are not explicitly taught to use phonetic components to retrieve phonological information, they still develop the awareness of phonetic components and make use of them when they need help with pronunciation. Therefore, our findings cannot be attributed to the "whole character method" in teaching Chinese reading.

To sum up, we argue that the occurrence of semantic substitution in native Chinese readers' performing read-aloud tasks is elicited by the unique informational structure of Chinese orthography. As explained above, our findings do not result from unique discourse reading skills or the "whole character method" in teaching Chinese reading. Moreover, our findings do not indicate that most native Chinese readers are deep dyslexic, Chinese orthography is logographic, or there is no universal rule in reading process. We interpret our findings as evidence of the salient role that semantics plays and the relatively weak activation of phonology in reading Chinese.

\section{References}

Abu-Rabia, S, and H. Taha. 2004. Reading and Spelling Error Analysis of Native Arabic Dyslexic Readers. Reading and Writing 17: 651-689.

Baluch, B, and D. Besner. 1991. Visual Word Recognition: Evidence for Strategic Control of Lexical and Non Lexical Routines in Oral Reading. Journal of Experimental Psycholog: Learning, Memory and Cognition 17(4): 644-651. 


\section{Hui-wen Cheng \& Catherine Caldwell-Harris}

Barry, C. 1984. Consistency and Types of Semantic Errors in a Deep Dyslexic Patient. In R. N. Malatesha, and H. A. Whitaker, eds., Dyslexia: A Global Issue, 311-337. The Hague: Martinus Nijhoff.

Béland, R, and Z Mimouni. 2001. Deep Dyslexia in the Two Languages of an Arabic/French Bilingual Patient. Cognition 82(2): 77-126.

Chan, Lily, and Lei Wang. 2003. Linguistic Awareness in Learning to Read Chinese: A Comparative Study of Beijing and Hong Kong Children. In C. McBride-Chang, and H. C. Chen, eds., Reading Development in Chinese Children, 91-106. Westport, Connecticut: Praeger Publishers.

Chen, H C, and H Shu. 2001. Lexical Activation during the Recognition of Chinese Characters: Evidence against Early Phonological Activation. Psychonomic Bulletin \& Review 8(3): 511-518.

Chen, H. C. 1992. Reading Comprehension in Chinese: Implications from Character Reading Times. In H. C. Chen, and O. J. L. Tzeng, eds., Language Processing in Chinese, 175-205. Amsterdam: Elsevier.

Chen, H.-C, G. B. Flores d'Arcais, and S. L. Cheung. 1995. Orthographic and Phonological Activation in Recognizing Chinese Characters. Psychological Research 58: 144-153.

Chen, May Jane, and Joseph Chak-Kau Yuen. 1991. Effects of Pinyin and Script Type on Verbal Processing: Comparisons of China, Taiwan, and Hong Kong Experience. International Journal of Behavioral Development 14(4): 429-448.

Chomsky, Noam. 1981. Lectures on Government and Binding. Dordrecht: Foris.

Coltheart, Max 1980. The Semantic Error: Types and Theories. In M. Coltheart, K. E. Patterson, and J. C. Marshall, eds., Deep Dyslexia, 146-160. London: Routledge \& Kegan Paul.

DeFrancis, John. 1984. The Chinese Language: Fact and Fantasy. Honolulu: University of Hawaii Press.

Frost, R, L. Katz, and S. Bentin. 1987. Strategies for Visual Word Recognition and Orthographical Depth: A Multilingual Comparison. Journal of Experimental Psychology: Human Perception and Performance 13(1): 104-115. 


\section{Semantic and Phonological Activation in Reading}

Geva, Esther. 2008. Facets of Metalinguistic Awareness Related to Reading Development in Hebrew: Evidence from Monolingual and Bilingual Children. In K. Koda, and A. M. Zehler, eds., Learning to Read Across Languages: Cross-linguistic Relationships in First- and Second-language Literacy Development, 154-187. New York: Routledge.

Kang, J. S. 1993. 現代漢語形聲字形符研究 [Analysis of Semantics of Semantic-Phonetic Compound Characters in Modern Chinese]. In Y. Chen, eds., 現代漢語用字信息分析, 84-98. Shanghai: 上海教育出版社.

Katz, L, and R. Frost. 1992. Reading in Different Orthographies: The Orthographic Depth Hypothesis. In R. Frost, and L. Katz, eds., Orthography, Phonology, Morphology, and Meaning. Advances in Psychology, 67-84. Amsterdam: Elsevier.

Laine, M, P. Niemi, J. Niemi, and P. Koivuselkä-Sallinen. 1990. Semantic Errors in a Deep Dyslexic. Brain and Language 38(2): 207-214.

Li, Ping, E. Bates, H. Liu, and B. MacWhinney. 1992. Cues as Functional Constraints on Sentence Processing in Chinese. In H. C. Chen, and O. J. L. Tzeng, eds., Language Processing in Chinese. Amsterdam: Elsevier.

Li, Ping, E. Bates, and B. MacWhinney. 1993. Processing a Language Without Inflections: A Reaction Time Study of Sentence Interpretation in Chinese. Journal of Memory and Language 32(2): 169-192.

Liberman, I. Y, A. M. Liberman, I. G. Mattingly, and D. L. Shankweiler. 1980. Orthography and the Beginning Reader. In J. F. Kavanagh, and R. L. Vanezky, eds., Orthography, Reading and Dyslexia, 137-153. Baltimore: University Park Press.

Liu, I.-M, J.-T Wu, I.-R Sue, and S.-C Chen. 2006. Phonological Mediation in Visual Word Recognition in English and Chinese. In P. Li, L. Tan, E. Bates, and O. J. L. Tzeng, eds., The Handbook of East Asian Psycholinguistics, 218-224. New York: Cambridge University Press.

Miao, X. C. 1981. Word Order and Semantic Strategies in Chinese Sentence Comprehension. International Journal of Psycholinguistics 8: 109-122.

Miao, X. C., G. P. Chen, and H. C. Ying. 1984. Reexamination of the Roles of Word Order and Lexical Meaning in Chinese Sentence Comprehension. Report of Psychological Science (in Chinese) 6: 1-7. 


\section{Hui-wen Cheng \& Catherine Caldwell-Harris}

Perfetti, Charles A, and S. Dunlap. 2008. Learning to Read: General Principles and Writing System Variations. In K. Koda, and A. M. Zehler, eds., Learning to Read Across Languages: Cross-linguistic Relationships in First- and Second-language Literacy Development, 13-38. New York: Routledge.

Perfetti, Charles A, and L. H. Tan. 1998. The Time Course of Graphic, Phonological, and Semantic Activation in Chinese Character Identification. Journal of Experimental Psychology: Learning, Memory, and Cognition 24(1): 101-118.

Perfetti, Charles A, and S. Zhang. 1991. Phonological Processes in Reading Chinese Characters. Journal of Experimental Psychology: Learning, Memory, and Cognition 17(4): 633-643.

Perfetti, Charles A., and S. Zhang. 1995. Very Early Phonological Activation in Chinese Reading. Journal of Experimental Psychology: Learning, Memory, and Cognition 21(1): 24-33.

Perfetti, Charles A, S Zhang, and I. Berent. 1992. Reading in English and Chinese: Evidence for a "Universal" Phonological Principle. In R. Frost, and L. Katz, eds., Orthography, Phonology, Morphology, and Meaning, 227-248. Amsterdam: Elsevier Science Publishers.

Shen, D., and K. I. Forster. 1999. Masked Phonological Priming in Reading Chinese Words Depends on the Task. Language and Cognitive Processes 14(5/6): 429-459.

Shu, Hua, and Ningning Wu. 2006. Growth of Orthography-phonology Knowledge in the Chinese Writing System. In P. Li, L. Tan, E. Bates, and O. J. L. Tzeng, eds., The Handbook of East Asian Psycholinguistics: Chinese, 103-113. New York: Cambridge University Press.

Tabossi, P, and L. Laghi. 1992. Semantic Priming in the Pronunciation of Words in Two Writing Systems: Italian and English. Memory \& Cognition 20(3): 303-313.

Wang, N. 1997. The Structure and Meaning of Chinese Characters and Words. In D. Peng, H. Shu, and H. C. Chen, eds., Cognitive Research on Chinese Language, 35-64. Jinan, China: Shandong Educational Publisher.

Weekes, B. S., M. J. Chen, and Y-B Lin. 1998. Differential Effects of 


\section{Semantic and Phonological Activation in Reading}

Phonological Priming on Chinese Character Recognition. Reading and Writing 10: 201-222.

Wu, J-T, and H-C Chen. 2000. Evaluating Semantic Priming and Homophonic Priming in Recognition and Naming of Chinese Characters. Chinese Journal of Psychology 42: 65-86.

Zhou, X, and W. D. Marslen-Wilson. 1996. Direct Visual Access Is the Only Way to Access the Chinese Mental Lexicon. In G. W. Cottrell, eds., Proceedings of the 18th Annual Conference of the Cognitive Science Society, 714-719. Mahwah, NJ: Lawrence Erlbaum Associates.

Zhou，Y. G. 1978. 現代漢字聲旁的表音功能問題 [To What Extent are the "Phonetics" of Present-day Chinese Characters Still Phonetic]. 中國語文 146: 172-177.

Zhou, Y. G. 1980. 漢字聲旁讀音便查 [Pronunciation of Phonetics within Compound Characters]. 長春: 吉林人民出版社.

Hui-wen Cheng

Boston University

Program in Applied Linguistics

96 Cummington St., Rm 246

Boston, MA 02215

hwcheng@bu.edu

Catherine L. Caldwell-Harris

Boston University

Department of Psychology

64 Cummington St

Boston, MA 02215

charris@bu.edu 